\title{
The postnatal growth delay in preterm infants and survey of the causative (risk) Factors
}

\begin{abstract}
Purpose: To analyze the factors which are associated with growth delay and malnutrition in preterm infants during first year of life.

Conclusion: Evaluation data of monofactor analyze in group of low body weight (LBW) infants showed statistically significant correlation of growth delay (GD) with late gestosis of pregnancy (OR-3,56), IUGR in a newborn $(\mathrm{OR}-4,40)$, formula feeding $(\mathrm{OR}-9,69)$ and anemia of a newborn (OR5,73). To optimize health care in preterm infants it is necessary to consider the factors which correlate with GD and give the recommendations how to prevent or treat pathological and deficit conditions.
\end{abstract}

Volume 5 Issue 7 - 2016

Starets O, Khimenko T, Mykhaylenko V

Odessa National Medical University, Ukraine

Correspondence: Starets Olena, Professor, Odessa National Medical University, Ukraine, Email estarets@yahoo.com

Received: May 25, 2016 | Published: December 06, 2016

Keywords: preterm infant, growth delay, risk factors, GD

Abbreviations: GD, growth delay; LBW, low body weight, VLBW, very low body weight; NEC, necrotizing enterocolitis; ART, assisted reproductive technologies

\section{Background}

Prematurity is the leading cause of newborn deaths and now second-leading cause of under 5 mortality after pneumonia. 15 millions babies are born preterm every year. Over 1 million children die each year due to complications of preterm birth. The rates of preterm birth are $5-18 \%$ in different countries and rises every year. In Europe it occurs in $5-9 \% .{ }^{1-7}$

Nowadays there are many reports which show and analyze the latest methods of perinatal medicine, and the majority gives information about outcomes of prematurity at the time of birth or admission from the hospital. In only $15,8 \%$ of researches held in low and middle outcome countries, authors followed-up infants for 2 years or more and less than $50 \%$ included studies report on growth outcomes. ${ }^{5,8-12}$

It is known that preterm birth is associated with postnatal growth and psychomotor delay and an increased risk of morbidity. The question of the hour is to study factors which affect the postnatal growth delay and malnutrition in preterm infants.

The intrauterine fetal growth and risk of preterm labor depends on various exogenous and endogenous maternal factors. Kerstjens JM et al., ${ }^{13}$ showed that intrauterine growth restriction (IUGR), maternal pregnancy obesity, being one of multiple, male sex were associated with the risk of developmental delay in early childhood in moderately preterm infants ${ }^{13}$ Also maternal distress is associated with low body weight and prematurity. ${ }^{14,15}$

Van der Reijden-Lakeman et al., ${ }^{16}$ reported that children with IUGR have high risk to be short stature in future. Early growth retardation may be associated with decreased head size, and decreased later cognitive functioning.

The level of neonatal medical care plays a great role in future health of the preterm. The systematic review Gladstone M, Oliver C, Van den Broek N, ${ }^{5}$ revealed that the studies documenting growth outcomes for babies who had received care in well-equipped health care facility reported that there was less evidence of differences in growth between babies born preterm and term. In Kenya, where neonatal special care facilities are much more limited, only $20-28 \%$ of infants born preterm reached the lower limit of normal growth by term. ${ }^{3,5}$

Recurrent episodes of hypoglycemia $(<2.6 \mathrm{mmol} / \mathrm{L}$ or $47 \mathrm{mg} /$ dL) were strongly correlated with persistent neurodevelopmental and growth deficits until 5 years of age. ${ }^{17}$ Poor postnatal weight gain in the first 2 weeks of life is an important and independent risk factor for retinopathy of prematurity requiring treatment. ${ }^{18}$

Extremely low body weight infants with short bowel syndrome (due to surgical treatment of necrotizing enterocolitis (NEC) were more likely to have growth failure than infants without short bowel syndrome. ${ }^{19}$ Multiple factors, including recurrent sepsis, malabsorption, postnatal steroid use, and cardiac diseases, may have contributed to poor nutritional outcome.

Having analyzed earlier the cohort of HIV-infected infants, we revealed that malnutrition and IUGR are more often documented in preterm babies. ${ }^{20-24}$

\section{Purpose}

To analyze the factors which are associated with growth delay and malnutrition in preterm infants during first year of life.

\section{Methods}

The study was held 2012-2014 on the base of University Child Health clinic №1 and Odessa Regional Charitable Rehabilitation Foundation for Handiccaped Children "Futurum". The main criteria to include a child into the range of study were gestation term under 37 weeks; body weight at the moment of birth under 2500 grams; absence of serious congenital defects and severe organic pathology. 150 children aged from 3 months up to 5 years who corresponds the criteria were selected (among them 74 boys and 76 girls) for the further analysis. All the children were divided in 3 groups depending on the birth body weight: $2^{\text {st }}$ low body weight (LBW) $(2499-1500)-67$, $2^{\text {nd }}$ very low body weight $($ VLBW $)(1499-1000)-45,3^{\text {rd }}$ extremely low body weight $($ ELBW $)(<999)-38$ patients. ${ }^{25-29}$

General clinical examination of children with evaluation of growth and retrospective analysis of development was held. To evaluate growth we made anthropometrical measurements following the order of Ministry of health of Ukraine №149 from 20.03.2008 “On 
acceptance of clinical Protocol of medical care of a healthy child under 3 years of age". The information we got was rated correspondingly: centile tables for preterm infants aging from 22 up to 50 weeks of gestation (Fetal-infant Growth Chart for preterm infants, WHO, 2006); graphics of standard deviations of physical development for children from 0 up to 5 years (WHO, Z-scores). We used anthropometrical calculator WHO Anthro, SISA online calculator to analyze achieved data. During the statistical analysis we studied the indicators of the growth of the children of the age 6 and 12 months.

\section{Results}

No significant differences were noticed in sex of patients. In the $2^{\text {st }}$ group 33 boys and 34 girls were examined, in the $2^{\text {nd }}-23$ boys and 22 girls, in the $3^{\text {rd }}-18$ boys and 20 girls. The average term of gestation was $34,42( \pm 2,11)$ weeks in the $2^{\text {st }}$ group, $29,76( \pm 1,93)$ weeks in the $2^{\text {nd }}$ group and $27,32( \pm 1,86)$ in the $3^{\text {rd }}$ group. Average birth body weight and birth body length were $1928,9( \pm 264,64) \mathrm{g} \& 43,42( \pm 2,76)$ $\mathrm{cm}, \quad 1277,36( \pm 139,16) \mathrm{g} \& 38,77( \pm 2,24) \mathrm{cm}, 908,47( \pm 81,66) \mathrm{g}$ \& $35,86( \pm 3,23) \mathrm{cm}$ respectively. The coefficient of variation of all the calculations did not exceed $13,8 \%$.

Frequency of growth delay (GD) among the children aged 6 months was $26,87 \%, 95 \%$ CI $[17,72 ; 38,52]$ in the $2^{\text {st }}$ group; $77,78 \%, 95 \% \mathrm{CI}$ $[63,73 ; 87,46]$ in the $2^{\text {nd }}$ group; $100 \%$ in the $3^{\text {rd }}$ group. Frequency of GD among the children aged 1 year was $7,46 \%, 95 \% \mathrm{CI}[3,23 ; 16,31]$, $33,33 \%, 95 \% \mathrm{CI} \quad[21,36 ; 47,93], \quad 63,16 \%, 95 \% \mathrm{CI} \quad[41,04 ; 80,85]$ relatively.

Table I Results of monofactor analysis of maternal risk factors

\begin{tabular}{|c|c|c|c|c|}
\hline \multirow{2}{*}{ № } & \multirow{2}{*}{ Factors } & \multicolumn{3}{|c|}{ Odds Ratio (OR) with $95 \% \mathrm{Cl}$} \\
\hline & & Totally in 3 Groups & I Group ( I 500-2499g) & II Group (1000-I499g) \\
\hline I & Using assisted Reproductive Technologies (ART) & $2,16[0,7 \mid-6,53]$ & $\mathrm{I}, 4 \mathrm{I}[0,23-8,43]$ & $2,25[0,24-20,84]$ \\
\hline 2 & Mother's Age (<15, >35 Years) & $\mathrm{I}, \mathrm{I} 6[0,35-3,87]$ & - & - \\
\hline 3 & Risk of Miscarriage in I Trimester & $|, 4|[0,65-3,09]$ & $\mathrm{I}, 06[0,32-3,57]$ & $4,70[0,53-4 I, 57]$ \\
\hline 4 & Risk of Miscarriage in II Trimester & $0,95[0,47-1,90]$ & $0,45[0,13-1,56]$ & $0,29[0,05-1,60]$ \\
\hline 5 & Late Gestosis & $\mathrm{I}, 00[0,38-2,60]$ & $3,56 *[1,09-11,54]$ & - \\
\hline 6 & Mother's Chronic Diseases & $\mathrm{I}, 68[0,66-4,28]$ & $0,64[0,12-3,35]$ & $0,38[0,07-2,03]$ \\
\hline 7 & Anemia & $\mathrm{I}, 48[0,54-4,05]$ & $2,5 \mid[0,59-10,67]$ & $0,83[0,|4-4,9|]$ \\
\hline 8 & Acute Respiratory Diseases During Pregnancy & $\mathrm{I}, \mathrm{I} 0[0,43-2,85]$ & $0,75[0, \mid 4-3,99]$ & $\mathrm{I}, 00[0,17-5,79]$ \\
\hline 9 & Hydramnion or Hypamnion & $0,98[0,28-3,39]$ & - & $\mathrm{I}, 16[0,12-1 \mathrm{I}, 74]$ \\
\hline 10 & Multiple Pregnancy & $\mathrm{I}, 02[0,49-2,09]$ & $\mathrm{I}, 26[0,42-3,77]$ & $2,66[0,49-\mid 4,46]$ \\
\hline II & Carriage of TORCH & $0,56[0,26-\mid, 2 I]$ & $\mathrm{I}, 03[0,33-3,25]$ & $0,3 \mid[0,06-\mid, 45]$ \\
\hline
\end{tabular}

Table 2 Results of monofactor analysis of infant risk factors

\begin{tabular}{|c|c|c|c|c|}
\hline \multirow{2}{*}{ № } & \multirow{2}{*}{ Factors } & \multicolumn{3}{|c|}{ Odds Ratio (OR) with $95 \% \mathrm{Cl}$} \\
\hline & & Totally in 3 Groups & I Group (I 5002499g) & II Group (1000-I499g) \\
\hline I & IUGR & $3,6 *[1,48-8,75]$ & $4,40 *[1,14-16,9]$ & $\mathrm{I}, 38[0,30-6,28]$ \\
\hline 2 & Lung Ventilation $\geq 7$ Days & $2,72 *[1,27-5,80]$ & $\mathrm{I}, 70[0,48-6,02]$ & $0,67[0,16-2,74]$ \\
\hline 3 & Tube Feeding $\geq$ I 4 Days & $2,53 *[1,24-5,15]$ & $\mathrm{I}, 38[0,43-4,45]$ & $0,24[0,04-I, 27]$ \\
\hline 4 & Breast Feeding $>3$ Months & $\mathrm{I}, 10[0,55-2,22]$ & $0,79[0,22-2,84]$ & $0,64[0,|4-2,9|]$ \\
\hline 5 & Formula Feeding & $2,54 *[I, 22-5,3 I]$ & $9,69 *[2,69-34,84]$ & $\mathrm{I}, 07[0,23-4,93]$ \\
\hline 6 & Anemia of Newborn & $3,54 *[1,64-7,64]$ & $5,73 *[1,62-20,26]$ & $0,36[0,08-1,63]$ \\
\hline 7 & Intraventricular Hemorrhage & $\mathrm{I}, 75[0,87-3,52]$ & $\mathrm{I}, \mathrm{I} 3[0,36-3,59]$ & $0,24[0,04-I, 27]$ \\
\hline 8 & NEC & $2,13[0,39-11,38]$ & - & $0,12[0,0|-|, 46]$ \\
\hline 9 & Severe Motor Delay & $\mathrm{I}, 15[0,52-2,55]$ & $\mathrm{I}, 50[0,43-5,20]$ & $0,04[0, I-I, 97]$ \\
\hline 10 & Severe Asphyxia & $5,28 *[1,69-16,5]$ & $0,90[0,08-9,27]$ & $3,16[0,35-28,14]$ \\
\hline
\end{tabular}

$\left.{ }^{*}\right)$, statistical significance of OR

Malnutrition (deficit of weight concerning the body length) was noticed among the children aged 6 months with the following frequency: $5,97 \%, 95 \% \mathrm{CI}[2,35 ; 14,37]$ in the $2^{\text {st }}$ group, $33,33 \%$, $95 \%$ CI $[21,36 ; 47,93]$ in the $2^{\text {nd }}$ group, $47,37 \%, 95 \%$ CI $[27,33 ; 68,29]$ in the $3^{\text {rd }}$ group. Among the children aged 1 year malnutrition was documented in $2,99 \%, 95 \%$ CI $[0,82 ; 10,25]$ of children of the $2^{\text {st }}$ group, $8,89 \%, 95 \%$ CI $[3,51 ; 20,73]$ of the $2^{\text {nd }}$ group, $15,79 \%$, $95 \%$ CI $[5,52 ; 37,57]$ of the $3^{\text {rd }}$ group.

At the age of 6 month the BMI in infants with VLBW and ELBW in comparison with LBW babies statistically significantly more often were lower than "-2"SD. This fact also confirms higher level of malnutrition in $2^{\text {nd }}$ and $3^{\text {rd }}$ group.

Studying the data of anamnesis vitae (life history) all children were separated in two groups: children who had GD in the age of 6 month (91 infants) and those who didn't have (59 infants). In a heuristic way we choose features which were potentially associated with GD in preterm infants during first year of life. Maternal factors: using assisted reproductive technologies (ART), age, risk of miscarriage, gestosis, acute and chronic diseases. Infant factors: IUGR, duration of lung ventilation and tube feeding, anemia of newborn, severe asphyxia and other.

ART was used in $16,67 \%, 95 \%$ CI $[9,80 ; 26,91] \& 8,47 \%, 95 \% \mathrm{CI}$ $[3,67 ; 18,35]$ cases relatively. Risk of miscarriage during $2^{\text {st }}$ trimester was present in $30,56 \%, 95 \%$ CI $[21,13 ; 41,95]$ women of $2^{\text {st }}$ group and in $23,73 \%, 95 \% \mathrm{CI}[14,69 ; 35,97]-2^{\text {nd }}$ group; during $2^{\text {nd }}$ trimester - in $44,44 \%, 95 \%$ CI $[33,54 ; 55,91]$ \& $45,76 \%, 95 \% \mathrm{CI}[33,70 ; 58,34]$ relatively. In group of infants with GD 20,83\%, 95\% CI [13,05;31,57] had chronic diseases, and $13,56 \% 95 \% \mathrm{CI}[7,03 ; 24,54]$ in $2^{\text {nd }}$. Carriage of TORCH group infections were a little beat more often seen in mothers of children with GD - 33,9\%, 95\%CI [23,14;46,63] to $22,22 \%, 95 \% \mathrm{CI}[14,17 ; 33,09]$, but it is not statistically significant. 
Almost similar results were shown in both groups for age of mother $\geq 35$ years $(9,72 \% \& 8,47 \%)$, late gestosis $(15,28 \% \& 15,25 \%)$, acute respiratory infections $(16,67 \% \& 15,25 \%)$, hydramnion and hypamnion $(8,33 \% \& 8,47 \%)$, multiple pregnancy $(36,11 \%$ \& $35,59 \%)$

Analyzing the neonatal period IUGR was documented more often in GD infants - $36,11 \%, 95 \% \mathrm{CI}[25,98 ; 47,65]$, to $13,56 \%, 95 \% \mathrm{CI}$ $[7,03 ; 24,54]$ in babies without GD. Respiratory care $\geq 7$ days and tube feeding $\geq 14$ days were held in $45,83 \%, 95 \% \mathrm{CI}[34,83 ; 57,26]$ \& $58,33 \%, 95 \%$ CI $[46,81 ; 69,01]$ children of $2^{\text {st }}$ group and in $23,73 \%$, $95 \% \mathrm{CI}[14,69 ; 35,97] \& 35,59 \%, 95 \% \mathrm{CI}[24,6 ; 48,34]$ of $2^{\text {nd }}$ relatively. Children with GD more often were on formula feeding - 48,61\%, $95 \%$ CI $[37,43 ; 59,93]$ to $27,12 \%, 95 \%$ CI $[17,44 ; 39,6]$ in $2^{\text {nd }}$ group. Also they more often had anemia of a newborn - 50,0\%, 95\% CI $[38,75 ; 61,25]$ to $22,03 \%, 95 \% \mathrm{CI}[13,35 ; 34,13]$. Severe asphyxia were documented in $27,78 \%, 95 \% \mathrm{CI}[18,76 ; 39,05]$ infants with GD and only in $6,78 \%, 95 \% \mathrm{CI}[2,67 ; 16,18]$ of infants without GD.

Statistically significant difference was not shown for frequency of such complication of preterm birth like intraventricular hemorrhage $(52,78 \% \& 38,98 \%)$, severe motor delay $(26,39 \% \& 23,73 \%)$ and $\operatorname{NEC}(6,94 \%$ \& $3,39 \%)$.

The monofactor analyze of chosen factors was held on the second stage of the study. The aim was to reveal the statistically significant probable difference of binary in $2^{\text {st }}$ (all infants with GD) and $2^{\text {nd }}$ (without GD) groups. The results can be observed in tab 1.1 and tab $1.2\left(2^{\text {st }}\right.$ column $)$. Also we did the same analyze separately in babies with LBW and VLBW ( $2^{\text {nd }} \& 3^{\text {rd }}$ column $)$.

Evaluating Odds Ratio (OR) with 95\%CI we didn't found the significant association of maternal factors and presence of GD in the age of 6 month (in the total group). From infant's factors GD was documented frequently in babies with IUGR ( $\mathrm{OR}-3,6)$, respiratory care $\geq 7$ days $(\mathrm{OR}-2,72)$, tube feeding $\geq 14$ days $(\mathrm{OR}-2,53)$, formula feeding (OR - 2,54), anemia of a newborn (OR - 3,54), severe asphyxia in birth $(\mathrm{OR}-5,28)$.

\section{Conclusion}

Evaluation data of monofactor analyze in group of LBW infants showed statistically significant correlation of GD with late gestosis of pregnancy $(\mathrm{OR}-3,56)$, IUGR in a newborn $(\mathrm{OR}-4,40)$, formula feeding $(\mathrm{OR}-9,69)$ and anemia of a newborn $(\mathrm{OR}-5,73)$. There were not found statistically significant difference of OR in VLBW infants for all factors. This may be due to general immaturity of those babies and requires further multifactorial analysis. To optimize health care in preterm infants it is necessary to consider the factors which correlate with GD and give the recommendations how to prevent or treat pathological and deficit conditions.

\section{Acknowledgements}

None.

\section{Conflicts of interest}

The authors declare no conflict of interest.

\section{Funding}

None.

\section{References}

1. Cooper PA, Sandler DL. Outcome of very low birth weight infants at 12 to 18 months of age in Soweto, South Africa. Pediatrics. 1997;99(4):537-544.
2. Ho JJ, Chang AS. Changes in the process of care and outcome over a 10-year period in a neonatal nursery in a developing country. J Trop Pediatr. 2007;53(4):232-237.

3. Were FN, Bwibo NO. Early growth of very low birth weight infants. $E$ Afr Med J. 2006;83(3):84-89 .

4. Beck S, Wojdyla D, Say L, et al. The worldwide incidence of preterm birth:a systematic review of maternal mortality and morbidity. Bull World Health Organ. 2010;88:31-38.

5. Gladstone M, Oliver C, Van den Broek N. Survival, Morbidity, Growth and Developmental Delay for Babies Born Preterm in Low and Middle Income Countries - A Systematic Review of Outcomes Measured. PLoS One. 2015;10(3): 0120566.

6. Blencowe $\mathrm{H}$, Cousens $\mathrm{S}$, Oestergaard $\mathrm{MZ}$, et al. National, regional, and worldwide estimates of preterm birth rates in the year 2010 with time trends since 1990 for selected countries:a systematic analysis and implications. Lancet. 2012;379(9832):2162-2172.

7. On approval of the protocol of care for newborn baby with low birth weight. MOH Ukraine, №584.

8. Pramana IA, Neumann RP. Follow up care of the preterm infant. Ther Umsch. 2013;70(11):648-652.

9. Guerra CC, Barros MC, Goulart AL, et al.. Premature infants with birth weights of 1500-1999 g exhibit considerable delays in several developmental areas. Acta Paediatr. 2014;103(1):e1-e6.

10. Al Hazzani F. Early or delayed enteral feeding for preterm growthrestricted infants:a randomized trial. J Clin Neonatol. 2012;1(4):181183

11. Alan S, Atasay B, Cakir U, et al. An intention to achieve better postnatal in-hospital-growth for preterm infants:Adjustable protein fortification of human milk. Early Hum Dev. 2013;89(12):1017-1023.

12. Belfort MB, Gillman MW, Buka SL, et al. Preterm Infant Linear Growth and Adiposity Gain:Trade-Offs for Later Weight Status and Intelligence Quotient. J Pediatr. 2013;163(6):1564-1569.e2.

13. Kerstjens JM, de Winter AF, Sollie KM, et al. Maternal and pregnancyrelated factors associated with developmental delay in moderately preterm-born children. Obstet Gynecol. 2013;121(4):727-733.

14. Rondó PH, Ferreira RF, Nogueira F, et al. Maternal psychological stress and distress as predictors of low birth weight, prematurity and intrauterine growth retardation. Eur J Clin Nutr. 2003;57(2):266-272.

15. Coletti MF, Caravale B, Gasparini C, et al. One-year neurodevelopmental outcome of very and late preterm infants:Risk factors and correlation with maternal stress. Infant Behav Dev. 2015;39:11-20.

16. van der Reijden-Lakeman. Growing Pains:Psychological Evaluation of Children with Short Stature After Intrauterine Growth Retardation, Before and After Two Years of Growth Hormone Treatment. Doctoral thesis. Erasmus University Rotterdam. 1996.

17. Duvanel CB, Fawer CL, Cotting J, et al. Long-term effects of neonatal hypoglycemia on brain growth and psychomotor development in smallfor-gestational-age preterm infants. J Pediatr. 1999;134(4):492-498.

18. Kim J, Jin JY, Kim SS.. Postnatal weight gain in the first two weeks as a predicting factor of severe retinopathy of prematurity requiring treatment. Korean J Pediatr. 2015;58(2):52-59.

19. Cole CR, Hansen NI, Higgins RD, et al. Very low birth weight preterm infants with surgical short bowel syndrome:incidence, morbidity and mortality, and growth outcomes at 18 to 22 months. Pediatrics. 2008;122(3):e573-e582.

20. Cheikh Ismail L, Knight H, Ohuma E, et al. Anthropometric standardisation and quality control protocols for the construction of new, international, fetal and newborn growth standards:the INTERGROWTH-22 ${ }^{\text {st }}$ Project. BJOG. 2013;120(Suppl 2):48-55. 
21. Cole TJ, Statnikov Y, Santhakumaran S, et al. Birth weight and longitudinal growth in infants born below 32 weeks' gestation:a UK population study. Arch Dis Child Fetal Neonatal Ed. 2014;99(1):F34F40.

22. On approval of the protocol of care for newborn baby with low birth weight. MOH Ukraine, №584. 2006.

23. Sulima OG. Modern problems of nursing and treating infants with very low birth weight //Health Ukraine, №18/1. 2007. 49 p.

24. Kotova NV. Physical development of infants born to HIV-infected women / NV Kotova, A. Elder // Perinatology and pediatrics. 2006;№4(28):111-116.
25. Neurology premature babies / A.B.Palchik, L.A.Fedorova, A.E.Ponyatishin, 2nd ed. Ext, M MEDpress, USA;p. 352s.

26. Mavropulo TK, Surkov DM. Health, born with extremely low birth weight. // Caring for a child. 2012;№7. - s32-s35.

27. Romanyuk, Smiyan K. Low birth weight - a problem only childhood?// Caring for a child №3:s3-s7.

28. On approval of clinical protocols of medical care for a healthy child under 3 years. MOH Ukraine of 20.03.2008 №149. 2012.

29. http://www.who.int/childgrowth/software/ru/ 